\title{
Cloning, dignity and ethical reasoning
}

Sir - Axel Kahn complains (Nature 388, $320 ; 1997)$ that his argument that "application to man of asexual reproduction and cloning represents an affront to human dignity" has been misreported by Nature and by John Harris's letter. He usefully restates his argument. This remains confused, like the all-tooinfluential French national committee report, which he helped to draft. It is important to try to cast light on the confusion.

Kahn ascribes autonomy to "the indeterminability of the individual with respect to external human will". He then asserts that "asexual reproduction would lead to... people whose bodily form and genetic make-up would be exactly as decided by other humans". This is an interesting example of the genetic determinism so rightly condemned by the French national committee report. Could even so distinguished a molecular biologist as Kahn actually predict in advance the adult height and body weight of any given clone? And, even if he could, why should that affect the autonomy of the clone's behaviour? After all, he rightly argues that the genetic make-up of a sexually reproduced person does not affect the autonomy of that person's behaviour.

Kahn then asserts that the relationship between 'creator' and 'created' would be "entirely new". But why, and in what respects? He further asserts that this "has obvious implications for human dignity”.
Again, why? At a Unesco meeting in May, another contributor to the French national committee report argued that cloning might lead to the creation of second-class citizens and even to a revival of slavery. The answer to that rhetoric is that humans, alas, have been well capable of creating secondclass citizens and slaves without any resort to the technology of cloning.

Could we now have a philosophically serious debate about the only morally appropriate proposed use of human cloning, namely Robert Winston's suggestion (Br. Med. J. 314, 913-914; 1997) that it might provide reproductive possibilities "for those men who exhibit total germ cell failure"? Winston points out that "even if straight cloning techniques were used, the mother would contribute important constituents - her mitochondrial genes, intrauterine influences, and subsequent nurture".

Let us make two assumptions: first, that in any society where this was thought appropriate, such cloning would be tightly regulated. Second, that many years of animal trials would have established that human clones were not likely to be at undue physiological risks compared with sexually reproduced humans. At this point, many would argue that the animal experiments would not be justified. If that argument were accepted, then, on those grounds alone, it would be right to rule out human cloning.

If, however, the necessary animal trials had been conducted, then what objections might be made to the limited application of cloning to overcome extreme cases of infertility? Kahn asserts, first, that the parental relationship would be "entirely new". Not so. We have many models of parenting: adoption, fostering, step relationships.... All may draw on the model of a two-parent nuclear family — in itself a relatively modern phenomenon. So, with cloning, there might be new aspects to the parental relationship. To argue that it would be "entirely new" is a piece of unjustified rhetoric: studies of new reproductive techniques suggest that families have little difficulty in assimilating them into traditional patterns (see, for example, J. Edwards et al. Technologies of Procreation: Kinship in The Age of Assisted Procreation, Manchester Univ. Press, 1993).

The second argument is that "an individual must never be used exclusively as a means". Kahn makes great play of the force of "exclusively". Perhaps he could explain why the cloning of a child for a man with total germ cell failure results in that child being used "exclusively as a means". How does that case differ from that of children resulting from medically assisted reproduction? The latter accounted in the early 1990s for almost 12 per cent of all births in France.

\section{David Shapiro}

Nuffield Council on Bioethics,

28 Bedford Square,

London WC1B 3EG, UK

\section{Back to basics}

Sir-Misleading references in scientific papers are common where a research group has studied the same topic for many years.

I recently gave a course on the energy metabolism of Escherichia coli. In a paper published in 1996, the authors say: "For $B$ galactosidase assay, cells were grown in a glucose-containing minimal medium ( $\mathrm{pH}$ 7.0) unless otherwise indicated ${ }^{4 \prime}$.

Reference 4 is a paper from the same research group published in 1990. In this paper the sentence reads: "For the Bgalactosidase assay, cells were grown in glucose $(40 \mathrm{mM})$ minimal medium (pH 7.0) (ref. 13) unless otherwise indicated".

Reference 13, published in 1985, reads: "For galactokinase assays and mRNA isolation, cells were grown in 50-ml volumes of glucose minimal medium ${ }^{32}$ supplemented with the indicated electron acceptor".

Finally, the composition of the medium is given in reference 32 .

This is a random example of a very bad habit. But why don't authors give the correct reference in every paper?

\section{Jukka Heinonen}

Department of Biochemistry,

University of Turku,

FIN-20014 Turku, Finland

e-mail:jukahe@utu.fi

\section{Alphabetical orders}

Sir - Recent correspondents ${ }^{1,2}$ have suggested that authors with initials earlier in the alphabet are more likely to be cited simply because they are more numerous, a fact borne out by examination of the distribution of surnames in the London telephone book.

However, comparing the citation rate of each letter with the number of telephone users of each letter is an inferior attempt to control for differences in the representation of initials to the method employed in the original study.

The correlation originally identified ${ }^{3}$ was between the number of citations for each paper published by authors of a particular initial and their surname's alphabetic position. This controls for the uneven distribution of initials among authors - if Zs are rare, they will publish fewer papers.

Perhaps the crude technique of using Londoners as a control removes the correlation because only a subset of papers are published by people with English names. Clearly there is still a case to answer, and given the growing importance of citation indices, one deserving of serious research.

\section{Tom Tregenza}

Department of Biology,

University of Leeds,

Leeds LS2 9JT, UK

e-mail:gentbt@leeds.ac.uk

1. Shevlin, M. \& Davies, N. O. Nature 388, 14 (1997)

2. Jaekel, K. M. Nature 386, 643 (1997)

3. Tregenza, T. Nature 385, 480 (1997) 